\title{
Management Strategy for Mechanical Trade Systems: Brief Review
}

Musaev Alexander Azerovich*, Anantchenko Igor Viktorovitch and Gazul Stanislav Mikhailovich

Department of IT and Control systems, St. Petersburg State Institute of Technology, Russia

\begin{abstract}
Brief review and comparative analysis of management strategies, implemented in creating of mechanical trading systems (or trading robots) are presented in the article. A requirement for formation of effective trading solutions is the key feature of formation of such strategies in conditions of chaotic dynamics of trade assets quotations. Their nonstationarity and extremely low level of predictability are specific for the majority of processes observed in electronic exchanges.
\end{abstract}

Keywords: Mechanical trade systems; Trade robot; Management strategy; Chaos; Chaotic dynamics; Exchange market; Forex

\section{Introduction}

Studies in the field of management of open nonlinear systems in chaotic environments are one of the most relevant directions of modern science. The respective area of a study combined into a new scientific paradigm - synergetics - allowed to have a fresh look at the nature of uncertainty. In particular, until the middle of twentieth century random events and processes were described in accordance with probabilistically statistical conception. One of its promoters, Laplace (1749-1827), didn't believe in accidents. It was him who derived the principle of determinism, according to which, all the processes are bound by strong cause effect relations. Absence of an unambiguous forecast was being explained solely by incompleteness of knowledge about all the aggregate of influences and factors of relationships between them. If a great know-all who received the name of "Laplace's daemon" existed, he could just look and give an accurate forecast on the development for arbitrarily distant future without any difficulty. Only papers of twentieth century scientists - [1] and some others, who rethought the outstanding results of Poincare (1854-1912) in the field of nonlinear differential equations, included the definition of a natural source of uncertainty, as a parameter instability of nonlinear open dynamic systems in so-called bifurcation points. This finding led to complete change of notions about emergence of uncertainty and predetermined an emergence of new scientific paradigm of nonlinear interactions. The notions of turbulence, gas and hydrodynamics, specifics of information (non-material) processes, peculiarities of sociodynamics, etc. were substantially changed [2]. There was a new, highest stage of uncertainty described by chaotic processes $[3,4]$.

The processes of change in quotations of currencies, stocks, raw material, and quotations of other assets in various capital markets became one of the vivid examples of chaotic dynamics. Hundreds of thousands of traders throughout the world are round the clock trying to forecast direction of currency instruments by time intervals in the range from several hours («scalping») to months and even years (the processes of strategic investment). More than $90 \%$ of traders are being ruined eventually. However, a few traders are still able to find weak links of order in chaos and steadily earn more than considerable capitals on their basis. This, in turn, means that the process of evolution of quotations is not pure chaos and holds local ordered segments in its structure. Two types of infrastructure and market data analysis are mainly used to detect these segments: Fundamental and technical.

Fundamental analysis (FA) uses available news and other information allowing to evaluate direction of movement of quotations in accordance with general economic, political and other considerations. Results of expert FA are regularly published on the broker and trader websites in the form of analytical reports and forecasts.
Technical analysis (TA) is related to formalized research of dynamics of quotations and uses all the arsenal of modern computer mathematics. In practice traders typically use a combination of both types of analysis.

Integrated informatization and automation [5] is an important trend of a present stage of exchange trade. The trading in electronic exchanges is being implemented globally through the internet network and automatic broker platforms [6]. Wide use of automated asset control systems and fully automatic systems - trading robots (TR) became a powerful innovative trend.

Brief reviewing of modern state of management in chaotic environments and comparative analysis of basic approaches to construction of TR focused on functioning in the mentioned conditions is the topic of this article.

\section{Trading Robots: Structure of Interaction and Main Objectives}

The structure of interaction of TR with a broker platform is presented in Figure 1.

TR is a multifunctional automatic device [7]. They are assigned to carry out the following tasks:

1. Support of continuous telecommunication connections with a broker platform

2. Provision of online entries of current quotations, their preprocessing and detecting of system component

3. Implementation by TA of dynamics of quotations and formation of managing solutions $\boldsymbol{D}$ meeting a given game strategy

4. Formation of controlling signals and their transmission to a broker platform

TA is the key tool of formation of solutions for TR. However, advanced trade robots allow [8]:

- Consider limitations shaped by a trader in the course of FA

*Corresponding author: Musaev Alexander Azerovich, Department of IT and Control systems, St. Petersburg State Institute of Technology, Russia, Tel: +7(812)494-9323; E-mail: amusaev@technolog.edu.ru

Received July 21, 2015; Accepted September 04, 2015; Published September 09,2015

Citation: Musaev A., Anantchenko I., Gazul S (2015) Management Strategy for Mechanical Trade Systems: Brief Review. Int J Econ Manag Sci 4: 284 doi:10.4172/21626359.1000284

Copyright: @ 2015 Musaev A., Anantchenko I., Gazul S. This is an open-access article distributed under the terms of the Creative Commons Attribution License, which permits unrestricted use, distribution, and reproduction in any medium, provided the original author and source are credited. 


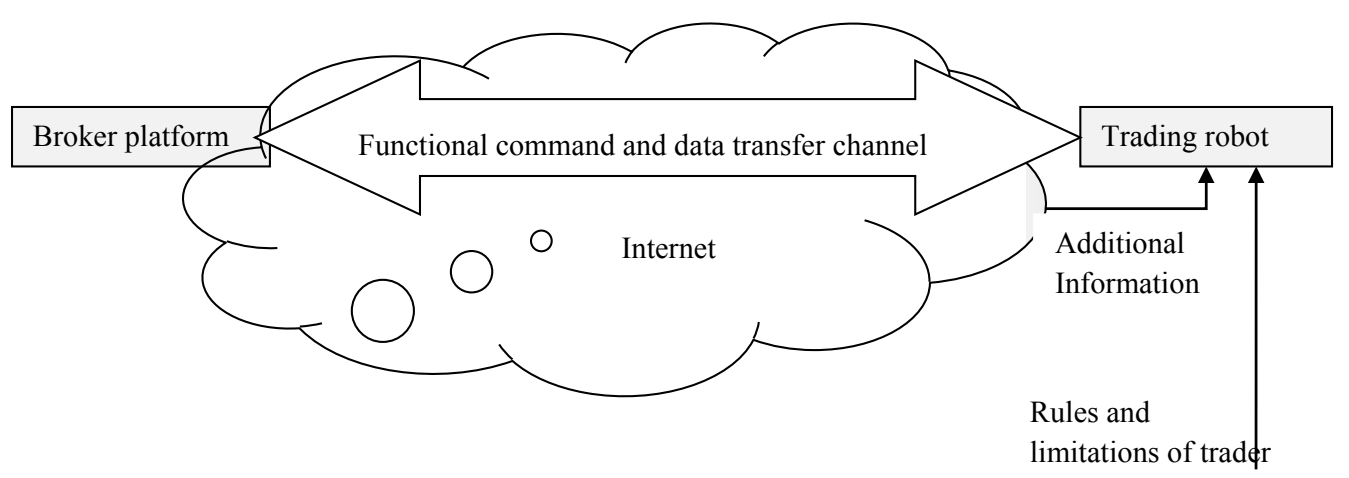

Figure 1: Structure of TR and broker platform interaction.

- Use state of t related capital markets for construction of governing strategies

- Consider data reflecting a market «mood» and other external factors

The newest «smart» robots are able to:

- Modify the management strategy on its own

- Carry out the development of rules and limitations following from content of analytical reports by means of Text Analisys tools

- Use the rules of risk and money management during modification of governing strategies.

It is obvious, that development of management solutions is the most important and decisive TR function. The results of trade speculations entirely depend on the effectiveness of a management strategy and solutions derived from it $[9,10]$. Therefore, to resolve the comparison task, TR first of all needs to carry out the comparison of model trade strategies defining their functioning.

In conclusion we will formulate the list of requirements, which a trade robot must meet:

1. TR must be a program application allowing obtaining sustainable receipt of profit from speculative operations in the financial e-market

2. The TR program represents realization of an algorithm of a sustainable and profitable for a steward strategy of speculation in the speculative market [11]

3. The source data for the program are represented by series of observations on dynamic process of pricing in the financial market with strongly expressed chaotic structure

4. The program must allow to determine allowable level of loss being locked in $S L$ preferably before opening an order for entering the position) and the level of profit $\boldsymbol{T P}$ fixation

5. Before the beginning of practical use, the trading system must be multiply testedt in demo accounts and then, in case of positive testing results - cent accounts [12]

\section{Stock exchange speculation: Basic definitions}

The main problem for developing an effective management strategy is the main feature of capital markets - their chaos. Corresponding phenomenon was reviewed in detail in the monograph of Peters [13].
In particular, analysis presented in it showed, that capital markets, contrary to abstract theories, were not effective and the quotations of assets did not reflect their real value.

The process of quotation change is much informational (and therefore, no inertial), subjective, ephemeral, dynamically unstable and hyper open for an infinite number of influences [14]. In other words, it corresponds to all the conditions of a chaos.

At present there are many definitions of chaos and chaotic processes [15]. In this article we will understand chaotic process as varying non periodic set of observations with an additive purely random stationary component. Such a pattern is sufficiently typical for quotation dynamics of market assets. Under the influence of numerous information impacts, the quotation observation series create a dynamic process of very complex nature almost not assuming formation of a long-term or medium-term forecast $[16,17]$.

A stochastic component which easily destroys traditional schemes of statistics processing [18] by virtue of its nonstationarity is present here unlike conditioned (or dynamic) chaos. The key attribute of a probability concept is absent -repeatability of experience.

\section{Trade transaction management}

The systems of trade transaction management in accordance with their automation level can be divided into "manual" systems, where decision is made by a person, and semi-automatic or automatic - trade robots [19].

The semi-automatic systems or the counselors form, but do not implement managerial decisions [20]. The final decision is made by the trader who is comparing a counselors' proposal to results of FA being badly formalized, so the trader makes a final decision and shapes an order for opening or closing the position.

Lastly, the trade robot does everything or almost everything on its own. In some cases, the trader can implement human-machine interface (HMI) of a robot, using some extra information (for example, from FA), also setting necessary restrictions. For example, with consideration for market conditions it can prohibit a robot to open a position down during specified time interval [21].

The considered asset management options have their advantages and disadvantages. But, in the opinion of analysts, a per cent of trade transactions in electronic exchanges executed by robots is constantly increasing. It is tied to both specificity of round-the-clock dealings in the forex market and high requirements for promptness 
of solutions that are formed. Besides, the need of quantitative analysis of multidimensional and multi-concern information is basically out of reach for a human brain [22].

From the other side, the complexity of automatic analysis of badly formalized qualitative information and presence of so-called intuition (of those ones who have it), makes a trader's participation expedient for systems creating managing decision [23].

However, the paper considers only the issues related to trade robots [24]. The automated counsellors are using the same software as TR. The only difference is in form of representation of a managing decision.

\section{Market models}

Application of formalized managing strategies presupposes using a model or group of models reflecting quotation dynamics of market assets at formal level. Different options of same model development were considered $[25,26]$.

In the opinion of the majority of specialists, it is extremely difficult to create a single model describing functioning of the financial market. In this connection, a group or a bank of models is created, the examples of which are:

\section{- A model of growing market}

- A model of stagnant market

- A model of volatile market

- A model of equilibrium market etc.

Models of growing and stagnant market typically have upward or downward trends. Such market can also be called "trend" market ("bullish" or "bearish") it's worth noting, that while estimating the trend and its force one should specify not only a trading instrument, but the time interval (time frame) used for analysis. Even if information of a junior timeframe (for example five-minute timeframe M5) is identified as a downward trend, it can look like a correction of an upward trend on older time frames [27-29].

In the model of volatile market the value of a price makes progressively-oscillatory motions with large amplitude, which allows opening diverse transactions in shorter or longer timeframes. This kind of trend movements are characterized by high correction shifts (kickbacks against trend), which should be considered while issuing stop orders.

Flat market prices (for considered financial instrument) almost don't change, so there's basically no trend, there's horizontal direction of movement (side trend or horizontal trend).

In practice, different types of the mentioned models can be used simultaneously. For example, a varying process with high level of volatility [30] can apply to the upward trend.

Figure 1 shows a chart for quotation dynamics of a currency pair of EURUSD during 150-day observation interval where the areas corresponding to different market models are clearly visible.

For any model of quotation change the task of building of an effective management strategy is trivial [31]. The problem is that it is impossible to guess what type of quotation dynamics should be expected in the nearest future, based only on trend analysis. The attempt of adaptation based on a prompt identification of dynamics type is also impossible to realize working with chaos [32]. The matter is that time, needed to identify a model is significantly higher than natural structural variability of structure of an observed process. Occurring lag leads to model inadequacy, and, as a result, inefficiency of a management strategy developed on its basis [33].

In conclusion, let's note that a market model will significantly change depending on a type of operations conducted on it [34] (Figure 2).

For example, a model of conversion operations market or a model of the futures market. In a number of cases it is expedient to take into consideration territory-time peculiarities of market. In particular, the biggest session of the Asia-Pacific market is in the interval of 03:0009:30 Moscow time, continent-European market - in the interval of 09:30-16:00, Great Britain market from 11:30 to 18:30, the US market from 17:30 to 00:30. Division on sessions is sufficiently conditional and, as it was indicated, corresponds with the time of maximum activity in one or another region.

\section{Software (SW) for trade transaction management}

Classification of software for managing trade operations on capital markets can be viewed in accordance with different criteria:

1. Based on the purpose of software one is to distinguish programs for automatic (or automated) control and the programs supporting manual control. In particular, manual control is supported by indicator programs and script programs (or utilities) [35]

Indicators are the programs, which inform trader about the state of a trading instrument, current account or accounts parameters (account balance, resources, and the number of open orders, amount of non-fixed profit (or loss) on open orders, the information on the level of margin, etc. Scripts (utilities) are programs started by a trader, automating one of the operations (or example, to close all the orders of used financial instrument). The software for automated management includes above mentioned trade counselors and TR.

2. Based on type of software platform, used for trading (for example, MetaTrader 4, MetaTrader 5 are currently popular on Forex market)

3. Based on algorithms realizing the trading strategy

4. Based on additional functionality (for example, the possibility of sending messages to a mobile phone, e-mail, etc.) [36]

5. Based on the price of software

6. Based on the possibility of using client software in different operating systems

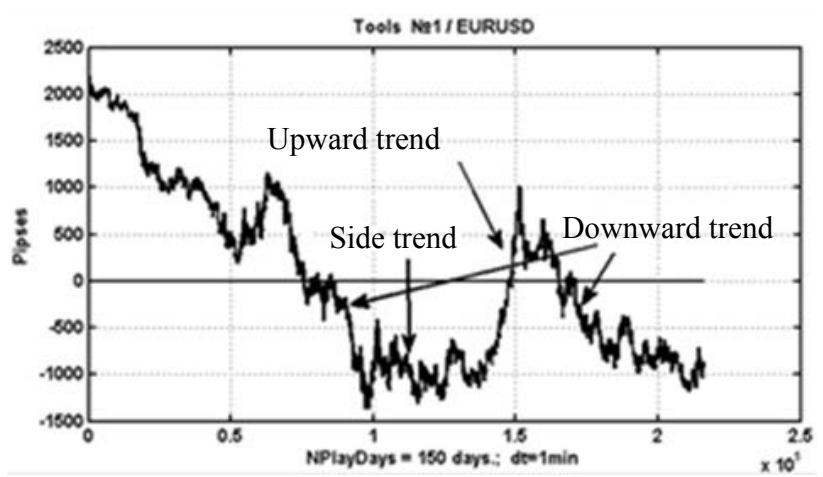

Figure 2: Trend types at different observation stages of a currency pair quotation changes during 150-day observation interval. 
7. Based on structural organization (single module, multi module, possibility of using dll libraries)

8. Based on the presence of additional tools to provide protection against unauthorized distribution and use (use of software or programhardware protection tools) and licensing schemes [37]

9. Based on the complexity of trading program (processing of situations with temporary unavailability of trading server on a part of a customer, for example, for the reason of disconnection, etc.)

Development of effective programs for trade on financial markets becomes complex with a range of difficulties. We will note the most significant [38] of them:

The theory of algorithms, considering the specificity of management in chaotic environments is developed weakly at present. There are no algorithms allowing to consistently receive large profits for all possible states of market.

Software is developed on language of programming recommended for a used trading platform (for example, the MQL language version 4 for a MT4 terminal and MQL version 5 for a MT5 terminal). Programming language includes functions for working with trade orders, which allows executing specific trade transactions, which cannot be programmed on another language, not based on architecture of a used trading platform. On the other hand, a language may be insufficient for implementation of a complex algorithm of a program [39]. In this case one has to use DLL libraries written in other programming language. Development of such libraries and the correct function call (interface issues of program code of different development environments) often belong to a category of nontrivial and complex tasks for applied programming.

In the course of trade the program must consider a possibility of emergencies and support algorithms to process them. For example, if connection with a trade server was lost and the open orders lost support, then at the point of reconnection it may require conducting of the operations, which the program was not aimed at. The need for tracking and processing of additional conditions lead not only to expanding of a program code and time for its development, it decreases the speed of program [40].

\section{Indicators - the software for supporting manual management of trade operations}

It is important to note, that modern traders who don't use automatic trading systems, don't trade by the "bare" chart, they use different kinds of indicators. The indicators, as was mentioned above, represent formalized indicators, allowing quantifying the nature quotation dynamics of currency or some other financial instrument. Indicator is, first of all, a trader's instrument. But the ideas underlying in indicators are extremely useful in development of formalized trade strategies and trading robots [41].

Based on functionality we can divide indicators into 3 groups.

Indicators of a trend (trends) constitute the first group - they specify direction of price movements simultaneously or with a slight delay, and determine the continuation or the change of the trend. For example, trend indicators operating on estimation of volume change (accumulation/distribution, volume rate of change), trend indicators estimating change of moving averages of different periods (Bollinger bands, moving average), etc. [42].

Indicators-oscillators allowing predicting the continuation or the change of the trend in advance or almost simultaneously - constituting the second group. For example, Average True Range, Ichimoku Kinko Hyo, Detrended Price Oscillator, Price Rate of Change, etc.

Psychological indicators constitute the third group; they define sentiment of market participants. For example, there is a eToro informer displaying information about current purchase/sale deals, opened by 1000 best traders in the network of social trading eToro (http://www. mctrewards.ru/files/etoro.zip) - visualization of information allows to evaluate a generalized opinion of leading experts about expediency of buying or selling of an examined financial instrument. If $90-99 \%$ of orders are opened for a purchase, the trend will most probably remain steady and it is expedient to consider a buying possibility, the same one refers to a situation of sale as well. If the ratio of buying and selling of orders is $50-80 \%$, it testifies that leading traders do not have a common opinion in forecasts about change of these assets.

\section{Management (trade) strategies}

The key element of any TR is a program for managing decision forming, based on a specific (or managing) strategy [43, 44]. In this connection, fundamental differences between TR developing methods are the differences in managing strategies [45]. We will consider the most widespread options of managing strategies assuming a formalized representation, i.e. assuming its realization in the form of a program for developing managing decisions for trading robot. Let's consider formalized task for building a trading strategy.

$\boldsymbol{Y}(\boldsymbol{t})$ - is the process of some asset quotation change. In the paper we use quotations of currency instruments on Forex e-market as an example. In order to decrease the influence of a purely random component, one can use different smoothing filters - exponential, Kalman filter, finite memory filter, moving averages, etc. Moving component $\boldsymbol{Y}_{s}(\boldsymbol{t})$ is some quazi system component, used for forming managing decisions $\boldsymbol{D}$. Here and further we talk about application of TA technologies, typical for building trading robots [46].

Note that electron nature of an exchange presupposes a digital form of observation sets $\boldsymbol{Y}(\boldsymbol{k}), \quad \boldsymbol{k}=1, \ldots, n$.

Managing strategy $\boldsymbol{S}$ is defined as a rule or a set of rules, providing functional representation $S: \quad\left\{Y_{k}, \ldots, Y_{k-T} ; I\right\} \stackrel{S}{\longrightarrow} D_{k}$. Here $T$ - depth of retrospective data used for present situation analysis, $\boldsymbol{I}$ is further information, for example, restrictions arising from a priori FA [47].

At its simplest, decision $\boldsymbol{D}_{\boldsymbol{k}}$, consists of the following possibilities:

- Refrain from some actions;

- Enter a game i.e. to open the position "up" or "down";

- Close previously opened position.

Various options of complicated solutions are also possible. For example, managing decision can contain the levels of automatic take profit $\boldsymbol{T P}$ and stop loss $\boldsymbol{S L}$.

Let's consider particular types of managing strategies allowing implementation in TR $[48,49]$

\section{Strategies on the basis of trend analysis}

The main provision for building trend strategies is opening of a position in the direction of a discovered trend of quotation change of currency instrument used [50]. 
Basic trend strategy is based on the use of decisive rule (criterion), in accordance with which a position up is opened, if the growth speed of an observed process $\boldsymbol{a 1}$, defined by slope of linear approximation on sliding window of observation of counts $\boldsymbol{w}$ (for example, minutes, when using timeframe M1), is higher than a critical value $\boldsymbol{a}_{1}{ }^{*}$. And on the contrary, position is opened under a condition $\boldsymbol{a}_{\mathbf{1}}<-\boldsymbol{a}_{\mathbf{1}}^{*}$.

It is obvious, that one can generalize this strategy, using two or three trend analysis on different observation windows. The example of such an approach is a strategy based on the criterion $\boldsymbol{K}_{2}$ using simultaneously two linear approximations on different sliding observation windows $\boldsymbol{w}_{1}$ and $\boldsymbol{w}_{2}$. A position up is opened under a condition of simultaneous excess of slopes in linear approximations of its critical values, i.e. $\boldsymbol{a}_{11}>\boldsymbol{a}_{11}^{*} \boldsymbol{\&} \boldsymbol{a}_{12}>\boldsymbol{a}_{12}^{*}$. On the contrary, position down is opened, if $a_{11}<-a_{11}^{*} \& a_{12}<-a_{12}^{*}$.

The further development of trend strategies is linked to application of higher order trends. In particular, one can consider a strategy using a linear approximation on a sliding window $w_{1}$ simultaneously with a square approximation on a sliding window $\boldsymbol{w}_{2}$. Position is opened up, under the condition $\boldsymbol{a}_{1}>\boldsymbol{a}_{1}^{*} \boldsymbol{\&} \boldsymbol{a}_{\mathbf{2}}>\boldsymbol{a}_{2}^{*}$ or down, under condition $a_{1}<-a_{1}^{*} \& a_{2}<-a_{2}^{*}$, where the parameters $a_{1}, a_{2}$ are essentially values of velocity and process acceleration on selected observation windows, and $\boldsymbol{a}_{1}{ }^{*}, \boldsymbol{a}_{2}{ }^{*}$.

For the first two strategies the estimates are of parameters of the slope of an approximating straight line $\boldsymbol{a}_{1}$ or $\boldsymbol{a}_{11} \boldsymbol{a}_{12}$, which can be computed on basis of least square method. However, if one uses polynomials in decisive statistics of higher degrees, the application of standard adaptation leads to a «mechanistic» approximation of least square method, where the estimates of coefficients of a polynomial cannot be interpreted as speed or acceleration of a process that is explored. This, in turn, deprives the possibility of process visualization while displaying trends graphically.

The trend strategies are beneficial in areas with clearly expressed trends to growth of quotations or quotation drop. But in the areas with the flat trend, they, as a rule, lead to a significant loss $[51,52]$.

\section{Strategies on the basis of oscillators}

This class of managing strategies is based on use of so-called oscillators, which are the estimates of propriety of current market value of a financial instrument. It is considered that the oscillators are indicators of «overbought» and «oversold» state of financial instrument. The examples of oscillators suggested for Forex are "Stochastics", "Parabolic", Relative strength index (RSI), Stochastic Expansion, etc.

A computational scheme on basis of dynamic limits of quotation observations variations $\boldsymbol{Y}(\boldsymbol{k}), \boldsymbol{k}=\mathbf{1}, \ldots, \boldsymbol{n}$ can serve as the simple example of building a managing strategy on the basis of oscillating indicator. As a result of smoothing with a low transmission coefficient one can construct a process imitating the value of a moving average $Y_{s}(k)=\alpha Y(k)+(1-\alpha) Y_{s}(k-1) \quad k=2, \ldots, n$. Essentially one can use a moving average procedure itself, or even other smoothing filter. The threshold values are set at the level of estimates of mean square deviation of a process $\delta(k)=Y(k)-Y_{s}(k), \quad k=1, \ldots, n$ :

$$
b=s(\delta(k, \ldots, k-m))=\left(\sum_{i=1}^{m}\left(\delta^{2}(k)\right)\right)^{\frac{1}{2}} /(m-1) .
$$

For optimization of the process of settlement one can vary threshold size, for example, in the range of $(0.75-2)$ s. Note that the process is stationary and estimate of mean square deviation is incorrect. Nevertheless, it is quite suitable for practical use in the first approximation.

The further decision is obvious. The revaluation criterion is that the quotation comes to the dynamic limit $\boldsymbol{Y}(\boldsymbol{k})>\boldsymbol{Y}_{\boldsymbol{s}}(\boldsymbol{k})+\boldsymbol{b}$. respectively, underestimation of an instrument is determined from a criterion $\boldsymbol{Y}(\boldsymbol{k})<\boldsymbol{Y}_{s}(\boldsymbol{k})-\boldsymbol{b}$. In the first case the robot opens position down, in the second case - up.

The proposed strategy can be quite effective at felt stations and clearly losing when there is an expressed trend in dynamics of quotations.

More complex ways of incorrect estimation of a currency instrument indication are related to the use of correlational and regression analysis technique. Correlational analysis allows specifying a stochastic linear relationship between different financial instruments. At the same time, one can consider not only intramarket instruments (for example, currency pairs in the forex), but intermarket relationships as well. For example, it is easy to set a relationship between the quotation of a currency pair of EURUSD and quotations of DJ index of a New York Stock Exchange or quotations of oil of a goods-raw material exchange.

In a case, if regressive evaluation of quotation turns out higher than the value of a current quotation and their difference exceeds a set threshold value $\hat{\boldsymbol{Y}}(\boldsymbol{k})-\boldsymbol{Y}(\boldsymbol{k})>\boldsymbol{b}$, it means that a financial instrument's being undervalued and indicates a possibility of opening a position up. And on the contrary, the condition can $\hat{\boldsymbol{Y}}(\boldsymbol{k})-\boldsymbol{Y}(\boldsymbol{k})<-\boldsymbol{b}$ serve as a recommendation for opening a position down.

It is obvious, that in conditions of strong trends this strategy can turn out ineffective. Besides, the situation is possible when not an instrument, but a regressor itself $[53,54]$ is incorrectly estimated. In this case it makes sense to verify a result on another instrument correlated with a working quotation or, to carry out assessment by the group of regressors using multiregressional analysis.

\section{Precedent strategies}

The precedent managing strategies (or strategies based on use of "patterns») are sufficiently typical even for manual asset control. In particular, many traders are trying to find standard patterns in quotation charts, which preceded standard changes of quotations. In particular, such patterns are well known - «wedge», «the pennant», «the flag», «the head are shoulders» etc. As a rule, traders underestimate cunning of chaos for which statistical experience means little. Quotation drop or a rise can follow one and the same figure with equal probability.

However, the evidence of absence or presence of after-effect requires professional analysis of data. Here, after-effect is understood to mean presence of changes of certain orientation immediately after an emergence of a pattern option $[55,56]$.

To enhance veracity of precedent decision, dynamics of quotations must be reviewed in the large (several years) observation interval and, using non-parameter measures of similarity, estimate probabilities of stable after-effects. To estimate the extent of similarity one can use different statistical measures of proximity: $\boldsymbol{T}_{\boldsymbol{0}}^{\mathbf{2}}$ Hotelling, KolmogorovSmirnov, $\omega^{2}$ Mieses, Wilkes, Kulbaka-Laiblera, the traces of Pillai et al. 


\section{Market-neutral strategies}

The market-neutral strategies (MNS) are strategies of revenue and risk which do not depend on market direction.

Paired trading is a variety of MNS being applied in the financial markets. A concept of cointegration developed by Engle and Granger [38] is theoretical basis of paired trading. For explanation of its nature we will introduce a number of definitions.

The ephemeral time series, which becomes stationary upon $n$ time differentiation becomes stationary is called integrated of order $\boldsymbol{n}$ one and is denoted as $I(n)$. Two integrated time series are $\boldsymbol{x}$ and $\boldsymbol{y}$ are cointegrated if a linear combination of these series $\boldsymbol{z}=\boldsymbol{a} \boldsymbol{x}+\boldsymbol{b} \boldsymbol{y}$ exists and makes a stationary process. If a certain linear combination of two time series has a smaller procedure of integration than a characteristic of integration of each of the series, it is said that the time series are cointegrated.

The paired trading strategy allows to profit on a short-term imbalance in yield or prices on assets with high degree of correlation. One and the same external factors have impact on a couple of similar companies from one sector of economy. Therefore, the share prices must even react to such events approximately the same. Therefore the short-term imbalance in an established ratio of prices must be compensated in direction of a long-term parity. Thus, if one security significantly rose or fell in the price in relation to other, short selling of a revalued security must be made and an undervalued security must be bought. When using this approach, the profit depends not on general direction of market movement, but on a future ratio of value of one security to the other. The trader relies on the statistical forecast about the return of a spread between two stocks to its medium importance.

Nevertheless, paired trading has a risk that the imbalance between assets keeps a trend character, i.e. a correlation between instruments becomes broken. Study of an issue of paired relationships in the forex market can be found [57].

\section{Martingale strategies}

Martingale strategies were initially used in gambling. The principle of a strategy is about successive lot growth by $40-100 \%$ in case of a loss. At the same time equal values of positive and negative result of play are usually set $(\boldsymbol{T P}=\boldsymbol{S L})$.

The strategy was firstly proposed by the French mathematician Paul Pierre Levy and arose from multiplication rules of probabilities for independent events. One can come to the same strategy proceeding from Bernoulli's theorem.

The strategy name originates from a French word of martingale denoting a part of horse harness - a semi-garrote limiting the position of a horse's head. If there is a wrong move, the martingale slowly tightens and doesn't let the horse to raise head. The similar device is used in the tackle of sail ships.

The disadvantages of such approach are sufficiently evident. The strategy requires a sufficiently large deposit and is extremely risky. In the opinion of experts, application of a martingale strategy allows to increase the possibility of profitable deals to $87 \%$ even in operation with a minimum deposit (4 financial margins). However, the risk is very high, around $62 \%$ and the deposit may be lost in one transaction sequence [57].

\section{Scalping strategies}

This approach, strictly speaking, is not a strategy, understanding under this term a set of rules unambiguously defining conditions of entering and leaving the market. This is some game ideology which one can describe more simply as an attempt for one to get small, but frequent profit with low risks $[58,59]$.

As a rule, a scalping trader is working with short timeframes M1M5 and tries to find a trend. After opening a position and receiving a minimum profit the position closes. Work is carried out within the day during which position can be taken 30-1000 times. At the same time the USD revenue for an operation of (0.1-0.2) USD with risk (0.02-0.03) can well suit the trader. In other words, the trader enters the market, scalped it and quickly left until the market punished him/ her for presumption.

Many experts consider speculation ideal technology for trading training; on the contrary, the others are sure it requires great experience. Some examples of day trade are described in Shmilovici et al. [17].

It is obvious; that such a game is possible only with small amounts of commission ("spreads") established by a broker. In practice, it must not exceed 3-4 pips. A large volume of lot is required for successful operation. In this connection they try to use a large leverage often of $1: 200-1: 500[41,60]$.

The scalping work is extremely rediouss and nervous. It can quite turn rational for the strategies of such a class to start using trade robots.

\section{Conclusion}

Despite a sufficiently large number of developed programs for trade in the financial markets, including Forex, one can make conclude that the vast majority of them are not universal and can bring profit only under certain conditions [61]. At the same time it is extremely difficult to determine observation intervals meeting conditions of effectiveness of these or other strategies. The delays related to the identification process do not allow switching to the required type of managing strategy in time, which can lead to significant losses, even the complete loss of a deposit. Nevertheless, the development of programalgorithmic software of trading robots realizing various variants of managing strategies represents not only scientific but also quite particular commercial interest. For example, on the portal of trading platform MT4 MQL4 Code Base (http://codebase.mql4.com/ru/) on 30.01.2014 93865 participants were registered and able to load 3219 programs (scripts) for trade in the Forex market, there are free, as well as commercial programs among them.

On another side the task of building effective managing strategies for trading robots is an applied task of a fundamental scientific issue of forecasting and management in chaotic environments. Even the partial solution of this problem, if it is ever made, discovers the broadest spectrum of practical applications in various fields of science, technology and socio-economic sphere.

\section{References}

1. Lorenz EN (1963) Deterministic non-periodic flow. Journal of the Atmospheric Sciences 20: 130-141.

2. Bosse T, Treur J, Jonker CM (2010) Formal analysis of design process dynamics. Al EDAM 24: 397-423.

3. Bashkirtseva I, Ryashko L, Chen G (2010) Analysis of stochastic cycles in the chen system. International Journal of Bifurcation and Chaos in Applied Sciences and Engineering 20: 1439-1450. 
4. Bashkirtseva I, Ryashko L (2013) Stochastic sensitivity analysis of noiseinduced intermittency and transition to chaos in one-dimensional discrete-time systems. Physica A: Statistical Mechanics and its Applications 392: 295-306.

5. Gerasimova VA (2009) Development of methodology for modeling trade using technical tools in the international currency Forex market. News of the Russian state pedagogical University 92: 105-109.

6. Vlasov VN (2009) The possibility of forecasting the price levels in the foreign exchange market. The Finance and the credit 24: 78-81.

7. Doolin AN, Rybalkin DA (2011) Selection of optimal strategy trader for decision making on the market. "Forex" Bulletin of the South-Russian state technical University. University Socio-economic Sciences 4: 41-47.

8. Delija DS, Kokurin DI (2009) Forecasting intraday distribution of the volume of trades. Russian economic magazine 2: 292-300.

9. Dyshaev MM, Sokolinskaja IM (2013) Representation of trade signals based on adaptive moving average Kaufman in the form of a system of linear inequalities. Computing mathematics and Informatics 2:103-108.

10. Emel'janova JeS, Kudinov DA (2009) Neutralization risk negative-a pleasant change the price of an instrument with the use of mechanical trading systems (robots-arbitrageurs") in crisis conditions the Resources of Information, supply, competition 2: 95-99

11. Kim DG (2009) Some questions of application of technical market indicators as tools for analysis and modeling of market behavior. Tax policy and practice: 13-15.

12. Peters EE (1996) Chaos and order in the capital markets: a new view of cycles, prices, and market volatility (2ndedn.) John Wiley \& Sons, NY, p. 288.

13. Portyakov V (2009) The global financial crisis: some implications. China Report 2: 159-161.

14. Ananchenko IV, Musayev AA (2013) Mathematical, informational technologies on the market "Forex" Matematicheskie i informaci-onnye tehnologii na rynke Forex. Saarbrucken: Lambert Academic Press. Lambert Academic Press, Saarbrucken, pp. 80.

15. Kaltwasser PR (2010) Uncertainty about fundamentals and herding behavior in the forex market. Physica A: Statistical Mechanics and its Applications 6 : $1215-1222$.

16. Gozim D, Guesmi K, Mahi DN (2013) On The enhancement of dc-dc converters nonlinear behaviors. Electrical Review 7: 45-49.

17. Shmilovici A, Kahiri Y, Ben-Gal I, Hauser S (2009) Measuring the efficiency of the intraday forex market with a universal data compression algorithm. Computational Economics 2: 131-154

18. Ananchenko IV, Musaev AA, Sushko AS (2014) For FOREX trading: development of system of indicators, programs. Lambert Academic Press, Saarbrucken, p. 147.

19. Vasil'ev LV (2010) Exchange trading: estimate of technical si-system. The New method of comparative assessment of the technicalsystem of exchange trading. Russian entrepreneurship 88-91.

20. Kolodko DV (2012) Expert short term forecasting currency market. Management economic system: electronic scientific journal 40: 99

21. Kondratenko VM (2013) Trading system, mechanical trading systems and trading robots: questions of terminology. Audit and financial analysis 323-325.

22. Niu Y, Liao D, Wang P (2012) Stochastic asymptotical stability for impulsive stochastic differential equations and it is application to chaos synchronization. Communications in Nonlinear Science and Numerical Simulation 2: 505-512.

23. Lien K (2005) Day Trading the Currency Market: Technical and Fundamental Strategies to Profit from Market Swings (2ndedn.) John Wiley \& Sons Inc, New Jersy.

24. Musayev AA (2010) Quod est veritas. Transformation of views on the sea component is intended monitored processes. Proceedings of SPIIRAS 15: 53 74.

25. Musaev AA (2011) Correlation analysis of the processes of change of standing stock and currency markets. SPIIRAN Proceedings of SPIIRAS 18: 5-18.

26. Musaev AA (2011) Modeling of quotations trading assets. Proceedings of SPIIRAS 17: 5-32.
27. Musaev AA (2010) Option for building robust trading-robot. Proceedings of SPIIRAS 12: 215-225.

28. Musaev AA (2009) Interaction trading robot with brokerage platform: the problem of robust control. Proceedings of SPIIRAS 10: 176-183.

29. Musaev AA, Barlasov IA (2012) Assessment of the status of stock markets on the basis of multivariate regression on a sliding window of observation. Proceedings of SPIIRAS 19: 243-254.

30. Musaev AA (2011) Modeling of quotations trading assets. Proceedings of SPIIRAS 17: 5

31. Musaev AA (2011) Statistical properties of linear forms currencies-tooling Proceedings of SPIIRAS 16: 141-159.

32. Musaev AA, Barlasov IA (2008) Simulation of chaotic processes in the capital markets. Proceedings of SPIIRAS 7: 255-264.

33. Muhametshin PP (2010) Innovative approach to forecasting volatility and direction of change of prices of shares on the stock market of the Russian Federation with the use of neural networks. Proceedings of the Free economic society of Russia 137: 366-373.

34. Myrzin KS (2011) Types of analysis on Forex. Problems of accounting and Finance 2: 51-53.

35. Pobedinskij AV (2007) Automated trading robots on the market of securities. The Finance and the credit 37: 35-39.

36. Pobedinskij AV (2009) Software trading on the stock market. Software products and systems 1: 29

37. Smirnov A, Levashova TN, Shilov (2009) Knowledge sharing in flexible production networks: a context-based approach. International Journal of Automotive Technology \& Management 9: 87-109.

38. Engle RF, Grander CWJ (1987) Co-integration and Error Correction: Representation, Estimation and Testing. Econometrics 55: 251-276.

39. Sal'nikova KH (2013) Exchange trade: robots vs. humans Scientific notes of the Russian Academy of entrepreneurship 34: 208-210.

40. Sal'nikova KH (2013) Trading robots on stock exchanges. Guide-employed17: 239-243.

41. Titov S, Vjaz'min SA (2007) Use of the method of weighted indicators for trading on the financial markets. Russian economic magazine 2:117-123.

42. Konnov VV (2013) About the strategies of trade with control drawdown deposit. Economic science 99: 161-165.

43. Kravchenko AV, Romanov AV (2012) Automated trading in the internationa currency market Forex. Siberian financial-Sava school 2: 62-69.

44. Logua RA (2012) Formation of the mechanism of making investmentgovernmental decisions during the dealing operations on the currency market. Bulletin of the Samara state University University 1: 218-223.

45. Lukashev AV (2011) Software Architecture, implementation of auto-automated trading system that uses technical analysis Scientific-technical Bulletin of information technologies, mechanics and optics 6: 128-132.

46. Molchanova M, Pechenkina AV (2011) Features of use of methods of fundamental and technical analysis when the Pro-gazirovanye prices on the property market of the region. Economics 3: 54-64.

47. Konnov VV (2013) Trendologist strategies and optimization robots. Economic science 98: 157-160.

48. Krjukov PA (2010) Typological classification of the exchange rate Proceedings of the Sworld 18: 6-9.

49. Lomakin $\mathrm{NI}$ (2013) Exchange trading robots in the conditions of information society. Scientific-methodical electronic journal Concept 10: 84-91.

50. Lomakin NI (2013) Features of exchange trade with the use of trading robots Proceedings of the Sworld 34: 59-63.

51. Lomakin NI (2013) Development of fuzzy control algorithm Fund against risk in exchange operations with shares of company. Fundamental research 7: 15341538.

52. Timofeev AG, Lebedinskaja OG (2012) Trading system and dynamics of economic bots on the exchange market. Initiatives-you XXI century 4: 65-68. 
Citation: Musaev A., Anantchenko I., Gazul S (2015) Management Strategy for Mechanical Trade Systems: Brief Review. Int J Econ Manag Sci 4: 284. doi:10.4172/21626359.1000284

Page 8 of 8

53. Titov S (2007) Adaptive decision making on financial markets. Applied econometrics 3: 27-43.

54. Haken G (1991) Information and self-organization. The macroscopic approach to the complex phenomena. Mir, p. 240.

55. Haken G (2003) The Secrets of nature. Synergy: the doctrine of the inter-under. IKI, p. 320

56. Martingale in the Forex market: sure whether steps to profit?

57. Chebotarev Ju A (2007) Trading robots replacing person. Banking 8: 78-80.
58. Janovskij LP, Borovikov IM (2010) Tools for operational decision making in the process of trading on FORTS market. Modern economy: problems and decision 4: 119-127.

59. Salpingocele Forex strategy.

60. Kushhov TO (2006) Automated trading system Forex. Social-economic and technical systems: Research, design, optimization 15: 3-8.

61. Lomakin NI, Grishankin Al (2013) The algorithm of management of the financial weighing the risk of the enterprise on the basis of fuzzy-method. The world of scientific discovery 12: 115-140. 